Article

\title{
Residential Racial and Socioeconomic Segregation as Predictors of Housing Discrimination in Detroit Metropolitan Area
}

\author{
Roshanak Mehdipanah ${ }^{1, *}$, Kiana Bess ${ }^{1}$, Steve Tomkowiak ${ }^{2}$, Audrey Richardson ${ }^{1}$, \\ Carmen Stokes ${ }^{3}$, Denise White Perkins ${ }^{4}$, Suzanne Cleage ${ }^{5}$, Barbara A. Israel ${ }^{1}$ and Amy J. Schulz ${ }^{1}$ \\ 1 School of Public Health, University of Michigan, Ann Arbor, MI 48109, USA; kbess@umich.edu (K.B.); \\ amricha7@gmail.com (A.R.); ilanais@umich.edu (B.A.I.); ajschulz@umich.edu (A.J.S.) \\ 2 Fair Housing Center of Metropolitan Detroit, Detroit, MI 48213, USA; stomkowiak@fairhousingdetroit.org \\ 3 School of Nursing, University of Michigan, Flint, MI 48502, USA; stokesca@umich.edu \\ 4 Institute on Multicultural Health, Henry Ford Health System, Detroit, MI 48202, USA; DWHITE2@hfhs.org \\ 5 Eastside Community Network, Detroit, MI 48215, USA; suzannecleage0@gmail.com \\ * Correspondence: rmehdipa@umich.edu
}

Received: 23 October 2020; Accepted: 9 December 2020; Published: 13 December 2020

\begin{abstract}
This study examined neighborhood racial and socioeconomic characteristics associated with housing discrimination (HD) in the Detroit Metropolitan Area, Michigan. Using novel neighborhood level data from the Fair Housing Center of Metropolitan Detroit in combination with the American Community Survey, incidence rate ratios (IRRs) were derived to examine associations between HD cases and percentage of homeowners, non-Hispanic White (NHW) residents, and median income. Models were stratified to examine these associations for race-, disability- and rent-related HD outcomes. Between 2008-2017, 988 HD incidents were reported. Independently, neighborhood proportion NHW, income, and homeownership were inversely associated with all-types of HD. Jointly, the neighborhood predictors remained significant indicators. Similar patterns were observed in race-, disability- and rent-related HD when neighborhood predictors were examined independently. In the joint models, household income no longer predicted race-related HD, while proportion NHW no longer predicted disability- and rent-related HD. Results suggest HD may be more frequent in neighborhoods with greater proportions of NHB or Hispanic residents, those with lower incomes, and greater proportion of rental households. These findings have great social and health implications and warrant further exploration of how HD contributes to social and health inequities in lower income, predominantly NHB and Hispanic neighborhoods and those with more renters.
\end{abstract}

Keywords: housing; discrimination; inequities; fair housing; segregation

\section{Introduction}

In the U.S., beyond the financial barriers of obtaining and maintaining a home, housing policies and real estate markets have disproportionately benefited non-Hispanic Whites (NHW) and those with higher incomes [1,2]. In an effort to address inequities in housing, the Fair Housing Act (FHA) of 1968, as amended, prohibits discrimination based on race, color, religion, sex, national origin, disabilities, and familial status [3]. Many state or local laws also prohibit discrimination based on marital status, sexual orientation, source of income, military and veteran status, or age. For example, Michigan's Elliot-Larsen Civil Rights Act also prohibits discrimination based on age and marital status [4], while the City of Detroit further prohibits discrimination based on public benefit status, sexual orientation, and gender identity or expression [5]. The FHA protects residents from housing discrimination, defined as unequal treatment, when trying to buy, rent, lease, sell, or finance a home 
based on the characteristics described above [3]. Beyond its protection against discrimination, the FHA is a critical piece of legislation that ensures all communities are accessible and provide opportunities for individuals and families to live with quality schools, healthy foods, and access to resources among other opportunities that will influence their lives $[3,6]$. Yet, despite these legal protections, housing discrimination continues to be a major social problem in the U.S. [7].

In 2018, the National Fair Housing Alliance reported approximately 31,202 cases of housing discrimination across the country, based on reports to various agencies including Fair Housing Organizations (FHO), the Department of Housing and Urban Development (HUD), Fair Housing Assistance Programs (FHAP), and the Department of Justice (DOJ). This represents a $14.7 \%$ increase from 2017 [7]. In both 2017 and 2018, discrimination based on disability was the dominant type of complaint (56.3\% of cases), followed by race-based discrimination (18.75\%) [7]. Discriminatory transactions were most commonly reported in the context of rental-related housing $(83.4 \%)$, while lower rates were reported at the time of purchasing a home including discrimination at the time of real-estate sales transactions $(2.62 \%)$, mortgage lending requests $(1.06 \%)$, and obtaining homeowner's insurance $(0.12 \%)$ [7]. Although discrimination at the time of purchasing a home may be less, these actions can have greater consequences on a household's possibility to attain stability and wealth accumulation through ownership [8]. Over the last twenty years there has been an increase in the number of reported cases. Although these increases may be attributed in part to improved reporting measures (e.g., awareness, education), the numbers have almost doubled in this period, raising concern that these trends may reflect real increases in discriminatory incidents [6]. Housing discrimination cases tend to be underreported, given the lack of awareness and education about these civil rights among the general population, furthering concern that the increase in reported incidents reflects exacerbations of housing discrimination $[9,10]$.

\subsection{Neighborhood Effects of Housing Discrimination}

Research on housing discrimination has generally focused on the consequences of race-based housing discrimination as it contributes to residential segregation and in turn, restriction of people of color to under-resourced and less desired areas [11-13]. Much of the literature has focused on largely two underlying causes for discrimination: prejudice, where housing agents withhold opportunities based on their racist views and beliefs against people of color; and profiteering, where largely, racists views and beliefs influence an agents expected rate of return [14,15]. In a paper by Galster [11], neighborhood influences on racial discrimination in housing are described as driven by two main theories, the customer prejudice theory and the rip-off theory. Within the 'customer prejudice' theory, Galster discusses how housing agents (realtors or landlords) seek to maximize their profits by using discrimination in order to maintain the business of their white customers [11]. Furthermore, upon establishing themselves only among white customers, by introducing minorities into an all-white neighborhood may result in retaliations and loss of business [11,16]. Therefore, in theory, discrimination would be more likely in all-white areas where there is belief that current white residents are prejudiced. In the 'rip-off theory', discrimination occurs in neighborhoods where there are a 'nontrivial' percentage of racialized minorities, where white residents are likely to purchase homes at a discounted rate while racialized minorities are willing to purchase at or above market value [17]. A third theory, the statistical theory, which has been used to study both sex-based and race/ethnicity-based discrimination, implies that rental agents, or landlords, are profit maximizer and, thus, from a cost or revenue perspective, ethnic or female-headed households are less profitable on average [18,19]. For example, female-headed households may have lower or less reliable income sources due to gender biases in the work force. This would then result in rent markup for females compared to their male counterparts as a way to compensate for this 'higher risk' that rental agents were assuming [20,21].

Despite the cause, discrimination not only impedes people of color from living in better neighborhoods, but it also prevents people from investing in neighborhoods that are predominantly of color [14]. These forms of discrimination have largely been referred to as differential treatment 
discrimination and disparate impact discrimination, where in the former, equally qualified individuals are treated differently due to their race or ethnicity, while in the latter, a general policy can disqualify people of color due to existing inequities [15]. For example, although landlords can request credit scores as part of the application process, there is existing evidence of racial inequities in credit scores, with African Americans and Hispanics having lower credit scores compared to their white male counterparts [22,23]. Yet, centuries of discrimination, redlining and exclusion of people of color have contributed to the racial wealth gap that exists in this country and captured by financial tools like credit scores $[12,22]$.

The consequences of housing discrimination experienced by African Americans and their communities, have resulted in barriers in education, employment, and economic growth [24,25]. Evidence also shows that discrimination impacts neighborhoods by lowering housing values as more African Americans move in [26], triggering the links between housing discrimination and neighborhood segregation, with the reduction of housing choice to areas with fewer opportunities, including decreased access to healthy foods, schools, and health care centers [27-29]. Racially segregated neighborhoods are more likely to experience disinvestment, affecting school resources and quality, resulting in higher drop-out rates, poor instructional quality, and low-test scores [30,31]. In a 2020 study by Acevedo-Garcia and colleagues, $46 \%$ of African American children and 33\% of Hispanic children were living in very low-opportunity neighborhoods compared to less than $10 \%$ of non-Hispanic white children [32], suggesting the potential intergenerational impacts of housing discrimination and neighborhood segregation.

Furthermore, racial segregation in neighborhoods has been linked to an array of poor health outcomes including high risks for low birth weight [33], cancer [34], and mortality [35], to name a few. Empirical research is needed to extend understanding of these place-based linkages to health, and to expand the very limited body of research on consequences of housing discrimination beyond race-based discrimination. In particular, there is surprisingly little empirical research documenting the implications of housing discrimination based on disability, the number one cause of housing discrimination in the U.S. [7]. Identifying the neighborhood characteristics associated with heightened housing discrimination cases is critical to inform efforts that address and prevent housing discrimination and its impacts on health inequities. By identifying characteristics of areas at heightened risk of housing discrimination, more efforts can be directed in educating tenants, landlords, and financial institutions on the FHA, with the goal of reducing incidents of discrimination.

\subsection{Housing Discrimination in Detroit Metropolitan Area}

The Detroit Metropolitan Area (DMA) is comprised of Wayne, Oakland, and Macomb counties. In 2018, approximately 3,880,929 people lived in the DMA. Within Wayne county, in 2018, 677,155 live in the city of Detroit, of which $78 \%$ were African American and $85 \%$ nonwhite [36]. Numerous factors have resulted in the DMA being one of the most segregated areas in the U.S. Once ranked among the nation's largest metropolises, industrial jobs drew non-Hispanic Blacks from the South and Canada, and residents from Mexico in the early 1900s [37,38]. In 1934, the Federal Housing Administration prohibited Blacks and other race/ethnic groups from living in certain parts of the DMA [39]. Beginning in the 1950s, federal investments in highways funds fostered the movement of white residents—often termed "white flight"—from the city to the surrounding suburbs. Simultaneously, many Detroit industries and other businesses moved out of the city into formerly rural communities enabled by highways, where large tracts of land were available. As central city factories relocated to outlying areas, racial discrimination in the real estate market, including federally backed home mortgages available to non-Hispanic Whites (NHW) but not non-Hispanic Blacks (NHB), perpetuated segregation, and reduced access of NHB to suburban housing and employment opportunities [38]. Furthermore, isinvestment from Detroit communities contributed to the movement of businesses out of the city, further contributing to un- and under-employment among Detroit 
residents [40]. The recession made Detroit's financial status worse resulting in the declaration of bankruptcy in 2013 and disproportionately affecting the racialized poor and city pensioners [40,41].

Today, racial distribution across the DMA continues to reflect these historical processes. Since the bankruptcy, and public services in the city have improved, there continues to be a lack of investment in affordable housing and current housing conditions [42]. Most of the houses in Detroit were built prior to the 1980s, and while there was a period of increased improvements among homeowners prior to the recession [43], since then there has been little upgrade or investment in their upkeep. Furthermore, after the economic recession, Detroit underwent some of the highest rates of foreclosures, both mortgage and tax related, in the country, resulting in many homeowners losing their homes and investors purchasing tax foreclosed homes at auction [42,44]. From 2000 to 2018, the Detroit homeownership rate fell from $55 \%$ to $47 \%$ [36,45].

The Fair Housing Center of Metropolitan Detroit (FHCMD) is the largest organization within the DMA to address local housing discrimination incidents [46]. It was established in 1977 and has since addressed more than 8000 complaints of unlawful housing discrimination and has assisted with complaints to resolve allegations. The FHCMD also receives housing related inquiries, frequently related to substandard housing and eviction proceedings. Often these evictions are a result of discrimination as well as lack of affordable housing and the prevalence of substandard housing. In addition to addressing housing discrimination complaints, the FHCMD provides education programs to inform entities within the housing system, including real estate agents, lenders, and landlords about the Fair Housing Act. In the DMA, the FHCMD receives higher reports of housing discrimination against people of color and people with disabilities, compared to other types of discrimination. They also address more cases that occurred during rental-related transactions compared to the purchase of a home.

In this paper, we examine neighborhood-level predictors of housing discrimination incidents. Specifically, we tested the following hypotheses:

(1) Housing discrimination is more likely to occur in neighborhoods with higher percentage of non-Hispanic Whites;

(2) Housing discrimination is more likely to occur in neighborhoods with higher median household incomes; and

(3) Housing discrimination is more likely to occur in neighborhoods with a higher percentage of homeowners. Next, we tested the hypothesis that

(4) each of these neighborhood characteristics contributes independently to an understanding of housing discrimination.

We tested each of these hypotheses using multiple discrimination outcomes (all-cause, race-based, disability-based, and rental-based) to assess the extent to which patterns were similar. We then ground our findings in existing theories that help us better understand drivers of housing discrimination in U.S neighborhoods.

\section{Materials and Methods}

This study was completed through a partnership established in 2017 between the Fair Housing Center of Metropolitan Detroit (FHCMD) and the Healthy Environments Partnership (HEP) [47,48]. The FHCMD has a longstanding track record addressing issues of housing discrimination and access in the DMA since 1977 when it was first established. Since then, FHCMD has been able to recover over 11 million dollars for plaintiffs in 500 closed litigations of housing discrimination cases. An estimated $\$ 1.5$ to $\$ 2$ million has also been recovered in non-disclosed settlements. The FHCMD also helped thousands of others obtain the housing of their choice without the necessity of litigation. In addition, FHCMD is involved in educating the public on fair housing rights throughout the DMA. The HEP is a long-standing community-based participatory research (CBPR) partnership that engages community, academic, and practice partners in a Steering Committee (SC) that oversees the research and action to understand and address social determinants of health in Detroit $[49,50]$. FHCMD provided housing 
discrimination data for this study and both FHCMD and the HEP SC were engaged in the development of the research questions and interpretation of the data. Select members from both groups participated as co-authors for this paper.

\subsection{Data and Measures}

Data was obtained through two different sources, the FHCMD discrimination cases and the American Community Survey. As part of the process, through a close collaboration with the FHCMD, we converted approximately 3000 paper copies of all housing discrimination incidents reported to FHCMD from 1977 to 2017 into electronic files, which were then converted into a dataset. These incidents were reported directly by individuals or referring agencies, to the FHCMD during this period. However, the dataset does not include cases reported directly to HUD or the Federal Bureau of Investigation (FBI) during this period. Furthermore, as described in the discussion section, housing discrimination cases are underreported and growing more complex due to the rise of online platforms used for real estate markets [7,51]. This paper focuses on the latest ten years of housing discrimination that occurred between 2008 and 2017. The dataset contains information for each case on where the discrimination occurred, the type of discrimination (e.g., race/ethnicity, gender, age, familial, and disability), and type of transaction (e.g., purchase or rental), among other information on the perpetrator. Since incidents could be reported by any individual and not necessarily the person experiencing the discrimination, data for the victim was incomplete and not used for this analysis. For the purposes of this study, we geocoded the location of the discrimination incident to obtain census tract (CT) information. Multiple cases against one source submitted by the same person were excluded from the total numbers, while multiple cases against one source submitted by different individuals were maintained in the count. CTs were used as a proxy for neighborhood to capture variability across geographic areas within the DMA. Data from the 2011-2015 American Community Survey was used to obtain neighborhood level data on percentage of housing units, sex, age, racial composition, education, homeownership status, and median housing income. We used ACS 2011-2015 to reflect neighborhood characteristics most closely over the 2008-2017 period for which discrimination data is available. A total of $1152 \mathrm{CTs}$ were included after eliminating $15 \mathrm{CTs}$ due to insufficient data (less than 100 residents in the neighborhood). The two datasets were merged, and the number of discrimination incidents were calculated for each neighborhood.

Dependent variables included all-types of discrimination incidents, race- and disability-related discrimination incidents, and rent-related housing discrimination incidents. All the dependent variables were included as count variables and aggregated at the census tract level across all years of the study period (e.g., number of cases occurring between 2008-2017 for each census tract). All-type discrimination incidents consisted of any reported incident to FHCMD between the periods of 2008-2017. Race-related discrimination cases grouped individuals who had either reported race or color as causes of the discrimination. Disability-related discriminations consisted of reported discrimination cases where the respondent reported having experienced discrimination due to mental or physical disabilities. Rent-related discrimination consisted of reported discrimination at the time of renting or leasing a property. We limited our research to these subgroups of discrimination characteristics as they were the most reported types of discrimination in the DMA during the study period (see Table 1). All other types and transactional discrimination incidents accounted for no more than $10 \%$ of all incidents. 
Table 1. Sample values with their corresponding standard errors (SE) for all study variables in the Detroit Metropolitan Area (DMA) at the neighborhood (census tract (CT)) level.

\begin{tabular}{|c|c|c|c|c|}
\hline & DMA Mean (SE) & Macomb Mean (SE) & Oakland Mean (SE) & Wayne Mean (SE) \\
\hline \multicolumn{5}{|l|}{ Demographics } \\
\hline$\%$ of women & $51.69 \%(0.12)$ & $51.42 \%(0.23)$ & $51.5 \%(0.18)$ & $51.88 \%(0.18)$ \\
\hline$\%$ of adults aged $18-64$ years & $62.84 \%(0.16)$ & $62.88 \%(0.27)$ & $63.22 \%(0.33)$ & $62.61 \%(0.23)$ \\
\hline$\%$ with high school education or more & $86.9 \%(0.29)$ & $88.4 \%(0.36)$ & $93.10 \%(0.30)$ & $82.9 \%(0.45)$ \\
\hline \multicolumn{5}{|l|}{ Neighborhood characteristics } \\
\hline$\%$ of Non-Hispanic White & $61.5 \%(1.04)$ & $82.37 \%(0.96)$ & $75.90 \%(1.27)$ & $46.0 \%(1.57)$ \\
\hline Median household income (per $100 \mathrm{k}$ ) & $50.06(0.69)$ & $51.87(1.08)$ & $67.88(1.40)$ & $40.11(0.80)$ \\
\hline$\%$ of owner-occupied households & $67.17 \%(0.63)$ & $74.0 \%(1.13)$ & $73.4 \%(1.20)$ & $61.30 \%(0.86)$ \\
\hline \multicolumn{5}{|l|}{ Housing discrimination outcomes } \\
\hline $\begin{array}{l}\text { Total number of housing } \\
\text { discrimination incidents }\end{array}$ & 988 & 143 & 304 & 541 \\
\hline $\begin{array}{l}\text { Percentage of total incidents } \\
\text { attributed to race }\end{array}$ & $54.25 \%$ & $54.55 \%$ & $58.88 \%$ & $51.57 \%$ \\
\hline $\begin{array}{l}\text { Percentage of total incidents } \\
\text { attributed to disability }\end{array}$ & $40.89 \%$ & $43.36 \%$ & $39.14 \%$ & $41.22 \%$ \\
\hline $\begin{array}{l}\text { Percent of total incidence that } \\
\text { occurred during rental transactions }\end{array}$ & $66.40 \%$ & $62.94 \%$ & $69.08 \%$ & $65.80 \%$ \\
\hline
\end{tabular}

The independent variables included neighborhood racial composition, homeowner status, and median household income, all assessed at the census tract level. Neighborhood racial composition was calculated by dividing the number of NHW by the total number of residents in the census tract. Percentage of homeowners was calculated as the number of houses occupied by their owners divided by the total number of occupied housing units (renters and owners) in the census tract. Median household income consisted of the median of the total income earned by all household residents aged 15 years and older for households within each census tract. Values were reported as per $\$ 1000$ to facilitate with the interpretation of the models. Control variables consisted of percentages of population aged 18-64, the percent females, the percent of residents aged 24 and older who have high school or more educational attainment, and the percentage of occupied housing units, all calculated at the census tract level.

\subsection{Data Analyses}

For the total sample and each county's subsample, we described and compared the neighborhood mean and standard deviation for all variables included in our study. To test hypotheses one through three, we ran twelve separate negative binomial regression models (a generalization of Poisson models that avoids the Poisson restriction on the mean-variance equality), regressing all-type discrimination, race-related, disability-related discrimination, and rent-related discrimination incidents on percentage of NHW, homeowners, and median household income. Models were controlled for age, sex, and education and used total occupied household units as the offset. Estimated coefficients were exponentiated to calculate incidence rate ratios (IRRs) and 95\% confidence intervals, where an IRR above 1 indicates a positive association and below 1 , a negative association between the dependent and independent variables. To test our fourth hypothesis, we ran four multivariate negative binomial regression models that included percentage NHW, household income, and homeownership simultaneously, to derive coefficients that were transformed to IRRs. Models were again controlled for age, sex, and education and used total occupied household units as the offset. All statistical analyses were completed using STATA version 15.0.

We developed maps to display the geographic distribution of housing discrimination cases and the three independent variables, percentage of NHW, median household income, and percentage of homeowners. All maps were created using ArcGIS Pro 2.4. 


\section{Results}

In Table 1, we present the descriptive statistics for the full sample and each county including the standard errors at the neighborhood level for the DMA.

The DMA averages for percentage of women and those aged between 18-64 years old were similar to each of the county means. The percentage of adults who had completed high school education or more was highest in Oakland, followed by Macomb and Wayne. The average percentage of NHW in the DMA was 61.5\%, with county averages ranging from $82.4 \%$ NHW in Macomb, $75.9 \%$ in Oakland, and Wayne County, with $46.0 \%$ NHW population. The mean median household income across census tracts in the DMA was $\$ 50,060$ : $\$ 67,880$ in Oakland, $\$ 51,870$ in Macomb and $\$ 40,110$ in Wayne County. Compared to the DMA average percentage of homeowners (67.2\%), with census tracts in Macomb county averaging $74.0 \%$, and Oakland $73.4 \%$, and census tracts in Wayne County averaging $61 \%$ homeowners. When it comes to housing discrimination outcomes, a total of 988 cases were reported to FHCMD between 2008 and 2017. Most of these cases took place in Wayne, followed by Oakland and Macomb. The two major types of discrimination were race and disability related. Oakland had the high percentage of race-related discrimination cases at $58.9 \%$ of all types of discrimination followed by Macomb (54.6\%) and Wayne (51.6\%). Macomb had the highest percentage of disability-related discrimination at $43.4 \%$ of all types of discrimination followed by Wayne $(41.2 \%)$ and Oakland $(39.1 \%)$. In all counties, most of the incidents occurred at the time of rent-related transactions. This included $69.1 \%$ of all types of discrimination incidents among Oakland's incidents, followed by Wayne $(65.8 \%)$ and Macomb (62.9\%).

Table 2 presents results from tests of Hypotheses 1-3, examining associations between neighborhood characteristics, entered individually into models, and all-types of housing discrimination, controlling for neighborhood demographic characteristics. Similar patterns (results not shown in the table) were observed for all other housing discrimination outcomes (race-, disability, and rent-related). All model findings are described below.

Table 2. Neighborhood-level all-type discrimination counts regressed on percent non-Hispanic White (NHW), median household income, and percent homeownership, independently.

\begin{tabular}{ccccccc}
\hline & \multicolumn{2}{c}{ Model 1 } & \multicolumn{2}{c}{ Model 2 } & \multicolumn{2}{c}{ Model 3 } \\
\hline & IRR & $\mathbf{9 5 \%}$ CI & IRR & $\mathbf{9 5 \% ~ C I ~}$ & IRR & 95\% CI \\
\hline $\begin{array}{c}\text { \% of NHW } \\
\text { Median Household Income } \\
\text { (per 100 k) }\end{array}$ & $0.98^{* * *}$ & $0.98,0.99$ & - & - & - & - \\
\% homeownership & - & - & $0.97^{* * *}$ & $0.96,0.97$ & - & - \\
\hline & - & - & - & - & 0.96 & $0.97,0.98$ \\
\hline
\end{tabular}

Neighborhoods with higher percentages of NHW residents were negatively, or inversely, associated with cases of all-type discrimination incidents (IRR $=0.98, p<0.001$ ), race-related discrimination $(\operatorname{IRR}=0.98, p<0.001)$, disability-related discrimination (IRR $=0.99, p<0.001)$, and rent-related discrimination (IRR $=0.98, p<0.001$ ). Similarly, median household income was inversely associated with rates of all-type discrimination (IRR $=0.97, p<0.001$ ), race-related discrimination (IRR $=0.98$, $p<0.001$ ), disability-related discrimination (IRR $=0.98, p<0.001$ ), and rent-related discrimination (IRR $=0.96, p<0.001$ ) reported. The percentage of homes that were owner-occupied was also inversely associated with all-type discrimination (IRR $=0.96, p<0.001$ ), race-related discrimination (IRR $=0.98$, $p<0.001$ ), disability-related discrimination (IRR $=0.96, p<0.001$ ), and rent-related discrimination (IRR $=0.96, p<0.001)$.

Table 3 presents results from tests of our fourth hypothesis, examining the extent to which there are independent associations between percent non-Hispanic White, household income and homeownership, and discrimination. No multicollinearity was observed among the independent 
variables. All-type housing discrimination was significantly inversely associated with percentage of NHW (IRR $=0.99, p<0.001)$, median household income (IRR $=0.99, p<0.05)$, and percentage of homeownership (IRR $=0.97, p<0.001)$. Race-related discrimination was similarly inversely associated with NHW residents (IRR $=0.99, p<0.001$ ) and percentage of homeowners (IRR $=0.97, p<0.001$ ), but was not associated with income. Disability-related discrimination was inversely associated with neighborhoods income (IRR $=0.96, p<0.001$ ) and percent of homeowners (IRR $=0.96, p<0.001$ ), but not significantly associated with percent NHW residents. Similarly, rent-related discrimination was inversely associated with neighborhood income (IRR $=0.99, p<0.001$ ) and homeownership (IRR $=0.97$, $p<0.001)$, but not with neighborhood percent NHW residents.

Table 3. Neighborhood-level discrimination counts regressed on percent NHW, median household income, and percent homeownership, simultaneously.

\begin{tabular}{ccccccc}
\hline & \multicolumn{2}{c}{ Model 1 } & \multicolumn{2}{c}{ Model 2 } & \multicolumn{2}{c}{ Model 3 } \\
\hline & IRR & $\mathbf{9 5 \%}$ CI & IRR & $\mathbf{9 5 \% ~ C I ~}$ & IRR & 95\% CI \\
\hline $\begin{array}{c}\text { \% of NHW } \\
\text { Median Household Income } \\
\text { (per 100 k) }\end{array}$ & $0.99^{* * *}$ & $0.98,0.99$ & $0.99 * * *$ & $0.98,0.99$ & 0.99 & $0.98,1.00$ \\
\% homeownership & $0.99^{* *}$ & $0.98,0.99$ & 0.99 & $0.99,1.01$ & $0.96^{* * *}$ & $0.96,0.97$ \\
\hline
\end{tabular}

${ }^{* *} p<0.05 ;{ }^{* * *} p<0.001$; All models were controlled for neighborhood age, female, and education.

Figure 1 provides the neighborhood distribution of all-types of housing discrimination cases in the DMA between 2008-2017, along with the neighborhood level predictors, percentage of NHW, median household income, and percentage of homeowners.

A

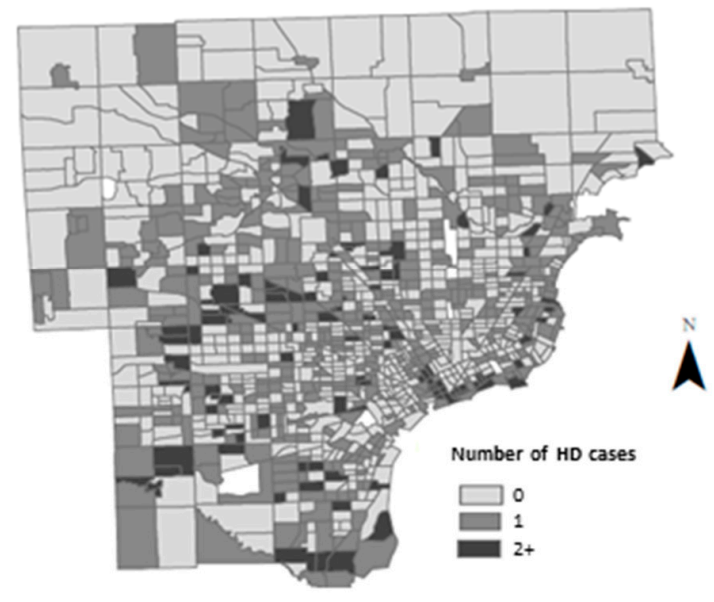

B

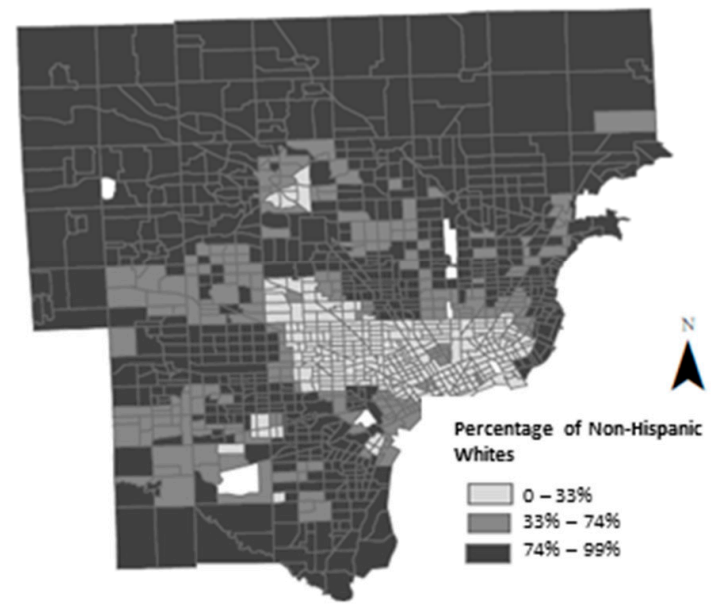

Figure 1. Cont. 
C

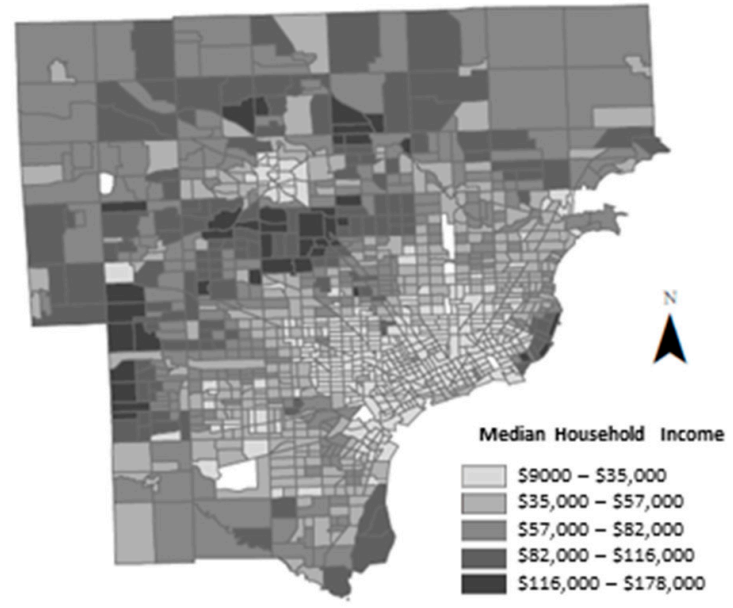

D

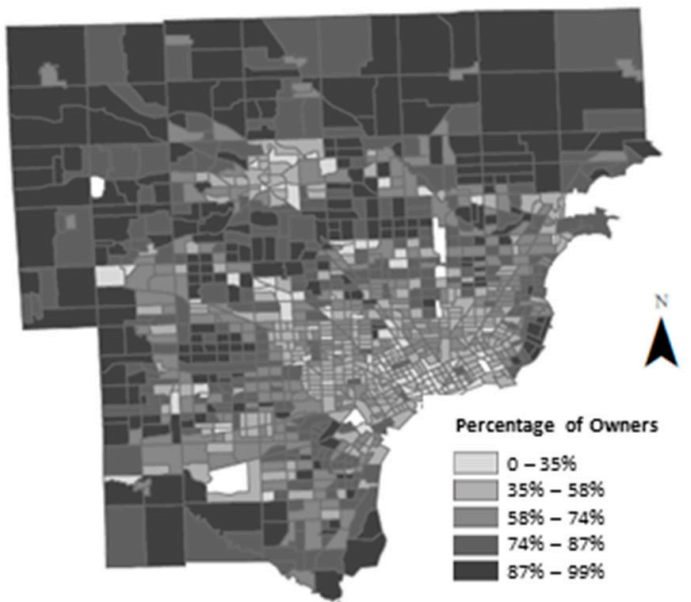

Figure 1. Neighborhood distribution maps for the DMA of housing discrimination cases (A), percent non-Hispanic whites (B), median household income (C) and percent of homeowners (D).

The housing discrimination map illustrates (Figure 1A) neighborhoods with no cases, one case, and two or more cases. Although cases are spread out across the DMA, there are more neighborhoods with two or more cases in the Detroit, Southfield, and Pontiac city areas. The second map (Figure 1B) illustrates the NHW distribution in the DMA, with most neighborhoods across the DMA except for Detroit city and some neighborhoods in Pontiac and Inkster, consisting of largely NHW residents. Clusters of neighborhoods adjacent of the city on the north, south, and west side tended to have more racially mix neighborhoods with only $33.0-74.4 \%$ of residents being NHW. Within Detroit, less than one quarter of the neighborhoods had $0-33.1 \%$ NHW residents. Maps of median household income (Figure 1C) and percentage of homeowners (Figure 1D), followed similar patterns with neighborhoods with high homeownership and high median household incomes, located on the peripheries of the DMA, while cities in Wayne County like Inkster, Taylor, and Detroit having lower percentages of homeowners and lower median household incomes. Similarly, trends are also seen in the Southfield and Pontiac area. The maps support findings from the statistical models.

\section{Discussion}

The main findings from this study were inconsistent with our initial hypotheses that housing discrimination incidents would be higher in neighborhoods with more NHW residents, higher median household incomes, and greater number of homeowners. Findings showed that individually, each of these neighborhood characteristics was associated with lower rates of overall housing discrimination, race-related discrimination, disability-related discrimination, and rent-related discrimination. When the neighborhood characteristics were analyzed jointly, although trends were in similar directions as the individual models, percent NHW was no longer a significant predictor of disability- and rent-related discrimination incidents, while median household income was no longer significant in reducing cases of race-related housing discrimination. It is important to contextualize these findings and below we discuss possible explanations for these findings and the broader implications they have on the field.

\subsection{Housing and Neighborhood Stability and Housing Discrimination}

Research has shown that homeownership status tends to provide more stability and freedom to make decisions around housing renovations and change [52-54]. Neighborhoods with greater percentage of homeowners tend to be more stable [8], more resources, and less crime [55], all positive for wellbeing [2]. These also tend to be the neighborhoods often deemed as higher opportunity areas $[56,57]$ and ones that housing discrimination incidents can prevent individuals to move into [6]. 
However, since renting opportunities are fewer in these neighborhoods, housing discrimination is often at the time of purchase. It may take the form of refusal to sell, refusal to provide a mortgage loan or insurance, discrimination in appraisal vales, or imposition of different terms or conditions on a loan including rates, points and fees, to name a few [58]. Within our sample, rent-related discrimination was more prominent than discrimination at the time of searching and/or financing a home. Although census tracts across the DMA tend to have more homeowners than renters, some census tracts in areas like Detroit have experienced a shift to more renters, especially after the influx of mortgage and tax foreclosures that occurred in the mid-2010s [44]. These shifts have disproportionately affected non-Hispanic Blacks [44]. Therefore, our findings that housing discrimination incidents decrease in neighborhoods with more homeowners may reflect the instability of rental properties, resulting in a higher turnover of renters and more opportunities for discrimination to occur within a property. Furthermore, with a lack of affordable housing, and an increase in renters, the high demand for housing could have led landlords to become more selective of their tenants, and in turn, biased in the process. This is of concern since many tax-foreclosed homes that went through auction were sold to multiproperty investor-buyers and speculators [59]. Such properties have been connected to higher rates of evictions. Under these conditions evicted tenants face great challenges in being rehoused, thus, evictions can become a precedent to homelessness. Those that do secure subsequent housing may accept inadequate housing with unfavorable terms, often in under-resourced neighborhoods. Additionally, landlords may refuse to rent to applicants with recent evictions, and evictions count against tenants applying for public housing. This is particularly concerning with the expected surge of evictions due to the COVID-19 pandemic and its economic consequences [60,61]. Furthermore, reports of inaccuracies in eviction recordings can have consequences for renters seeking access to high opportunity neighborhoods and public housing $[62,63]$.

When it comes to health, inadequate housing conditions can lead to toxic exposure, asthma, and injury, while eviction has been linked to both physical and mental problems including suicide [64-66].

\subsection{Legacy of Redlining Practices}

Most of the research considering housing discrimination has focused on race-related incidents. Contrary to our hypothesis, the rate of race-related housing discrimination incidents went down in neighborhoods with higher percentages of NHW residents. As described above, these trends may reflect higher rates of homeownership (and lower rates of rental) in predominant NHW neighborhoods, largely in Oakland and Macomb counties, which are the suburbs of Detroit city. These historically established suburbs were largely made possible through strict zoning codes that enticed white homeowners to move from the city center's commercial and high-dense districts in the early 1900s. These exclusionary zoning ordinances became exceedingly problematic in the late 1960s and early 1970s as more jobs moved to the suburbs, taking economic opportunities away from the city and into largely white and wealthy neighborhoods [38,40]. Although judicial enforcement of racially restrictive covenants and zoning ordinances was prohibited in the early case of Buchanan $v$. Warley, 245 U.S. 60 (1917) [67], exclusionary zoning tactics based on income prevailed, helping maintain the existing segregated metropolitan landscape in the DMA [68,69]. For example, exclusionary zoning was implemented that endorsed structures of low density or large lot sizes, which in turn came at a high housing price, which were often unattainable by low- and middle-income African Americans. Furthermore, such single-family housing opportunities were rarely rented and, thus, further excluded marginalized populations $[68,70,71]$. Although there have been efforts to reverse the effects of such zoning practices, including the promotion of inclusionary zoning guidelines in Detroit, the consequences of such practices continue to exist [72].

Another potential explanation could be an under-reporting of cases to the FHCMD in predominantly NHW neighborhoods. Although the Fair Housing Act was implemented in 1968, there continues to be a lack of public awareness around what constitutes housing discrimination $[9,10]$. This lack of awareness surrounding the potential protections from the law, could also be a driver in 
preventing individuals and families from even seeking residence in these neighborhoods. The legacy of redlining practices of the 1930s through the Home Owners Loan Corporation (HOLC), where banks drew red lines on maps around neighborhoods that were predominately black and restricting access to lending in these places, continues through illegal practices in the housing market including predatory lending and real estate steering [73,74]. Existing evidence from such illegal steering was captured in a 2006 NFHA report, where African Americans were offered fewer home options in primarily African American DMA neighborhoods, while NHW were shown homes mostly in NHW neighborhoods [75]. However, as described earlier, housing discrimination cases tend to be underreported given the lack of awareness of these civil rights $[9,10]$. Therefore, there could be unreported cases of realtors steering individuals and families of color to neighborhoods that are not predominantly NHW, resulting in no case of discrimination being reported for a single property, which this dataset captures. Continued awareness for buyers and renters, along with enforcement of the FHA is essential to address such practices. In addition, such education and awareness must also be updated to include information on discriminatory processes used on online platforms and social media for real estate and housing marketing. In 2019, HUD charged Facebook with violating FHA for allowing and facilitating housing discrimination through its advertising platform [76]. By using Big Data analytics, Facebook allowed advertisers to exclude individuals from certain housing ads based on national origin, religious affiliation, ZIP code, and interests in specific in African American or Hispanic cultures $[77,78]$. Although Facebook has since changed their advertising platform, this case serves as an example of how Big Data analytics can result in discriminatory practices through the introduction of human and machine bias [78]. As a result of these complexities, awareness and education on the FHA should be constantly updated.

Despite the passage of the Fair Housing Amendments Act in 1988 and the Americans With Disabilities Act in 1990, as well as the Supreme Court decision in Olmstead v. L.C. and E.W. in 1999, that increased access to employment, public services, and other resources, housing choice and opportunities continue to be limited by discrimination and lack of accessibility [79]. Research continues to show associations between low neighborhood socioeconomic status, residential instability, and greater disorder with higher prevalence of physical and mental disabilities [80,81]. While there has been a significant push to improve awareness and education for people with disabilities and their fair housing rights, homes are still being built without meeting the design and construction requirements under the Fair Housing Act that make housing more accessible to persons with disabilities [79]. Furthermore, reasonable modifications are generally at the tenant's expense unless the housing provider receives federal financial assistance, which would be considered a fair housing violation [82].

\subsection{Limitations}

The research presented here is a first step in better understanding where housing discrimination occurs to focus services and awareness to those areas. However, there are some limitations in our data and analysis. Our dataset is exclusive to individuals who reported cases to the FHCMD. The dataset does not include cases reported directly to the HUD or the Federal Bureau of Investigation (FBI), although it is more common for FHCMD to be the first source of contact. We included all cases reported to FHCMD in which an intake form was completed and a recommendation for further investigation was determined by FHCMD staff. Another limitation was in the analysis, where although our models were offset with the total occupied housing units, an ideal measure would have the total number of housing-related transactions (sales, rentals, loans administered) each year. With this information, a rate could be developed and provide a closer measure of how severe housing discrimination incidents are in each area. While this may be easier to obtain from realtor listings for home sales, rental listings are not centralized and more difficult to obtain. 


\section{Conclusions}

Contrary to our hypotheses, findings reported here suggest that housing discrimination incidents in the DMA were lower in neighborhoods with greater proportions of NHW, homeowners, and higher median household incomes. We discuss the potential for housing discrimination to perpetuate segregation by maintaining racialized residents in certain neighborhoods. Our findings suggest that housing discrimination is more likely to occur in neighborhoods with higher percentage of NHB residents, more renters, and lower median household incomes. At the same time, individuals and families looking for residence in those neighborhoods are also more likely to be renters, people of color, and/or lower income, disproportionately exposing them to housing discrimination incidents, compared to those seeking housing in neighborhoods with more NHW residents, higher homeownership and greater income. This contributes to greater inequity gaps amongst those seeking home in these different neighborhoods. At the same time, although there has been an increase in efforts to raise awareness on disability-related discrimination, when it comes to building and reforming houses, there exists uncertainty on what constitutes discrimination and what is a tenant's responsibility. More information is needed to help improve existing policies, raise awareness on housing discrimination, and strengthen fair housing enforcement, to address housing and health inequities in the DMA.

Author Contributions: Conceptualization, R.M., K.B., S.T., A.R., C.S., D.W.P., S.C., B.I., A.S. authors contributed to the conceptualization process; methodology, R.M., K.B. and A.J.S.; data analysis, A.R., K.B., S.T., A.J.S., C.S., D.W.P. and R.M.; writing - original draft preparation, R.M., K.B., B.A.I., A.J.S.; writing—review and editing, R.M., K.B., S.T., A.R., C.S., D.W.P., S.C., B.A.I. and A.J.S. authors reviewed and contributed to the final manuscript. All authors have read and agreed to the published version of the manuscript.

Funding: This research was funded by the Michigan Institute for Clinical \& Health Research (UL1TR000433), National Institute on Minority Health and Health Disparities (R24MD001619), National Institute of Environmental Health Sciences (R01 ES022616 and P30ES017885), and the Fred A. and Barbara M. Erb Family Foundation.

Acknowledgments: We would like to thank the Healthy Environment Partnership Steering Committee: Chandler Park Conservancy, Detroit Health Department, Detroit Hispanic Development Corporation, Eastside Community Network, Friends of Parkside, Henry Ford Health System, Institute for Population Health, University of Michigan School of Public Health, and community members-at-large, for their contributions to the work described here. We would also like to thank the students who have contributed to the creation and management of the housing discrimination database over the last couple of years including Camille Anoll, Sarah Koslakiewicz, Jaclyn Martin, Nadia Karizat, Sheridan Tobin, Danya Ziazadeh, Manuel Avina, Caylin A. Luebeck, Jamison Koeman, Shanea Condon, Jordan Pond, Kevin Hu, Alexa Eisenberg and all of our volunteers.

Conflicts of Interest: The authors declare no conflict of interest. The founding sponsors had no role in the design of the study; in the collection, analyses, or interpretation of data; in the writing of the manuscript, and in the decision to publish the results.

\section{References}

1. Gibson, M.; Petticrew, M.; Bambra, C.; Sowden, A.J.; Wright, K.E.; Whitehead, M. Housing and health inequalities: A synthesis of systematic reviews of interventions aimed at different pathways linking housing and health. Health \& Place 2011, 17, 175-184. [CrossRef]

2. Mehdipanah, R.; Schulz, A.J.; Israel, B.; Mentz, G.; Eisenberg, A.; Stokes, C.; Rowe, Z. Neighborhood context, homeownership and home value: An ecological analysis of implications for health. Int. J. Environ. Res. Public Health 2017, 14, 1098. [CrossRef] [PubMed]

3. The Fair Housing Act, Title VIII of the Civil Rights Act of 1968, Pub. L. 90-284 (Apr. 11, 1968), as amended by Fair Housing Amendments Act of 1988, Pub. L. 100-430 (Sept. 13, 1988). The Fair Housing Act is codified at 42 U.S.C. $\$ \S 3601-3619$. Available online: https://www.justice.gov/crt/fair-housing-act-2 (accessed on 10 February 2020).

4. Elliott-Larsen Civil Rights Act, Act 452 of 1976, M.C.L. $\$ \S 37.2501-37.2507$. Available online: https://www. michigan.gov/documents/act_453_elliott_larsen_8772_7.pdf (accessed on 20 October 2020).

5. Detroit Code of Ordinances, Chapter 23 - Human Rights, Article VI - Real Estate, Insurance and Loan Practices, §§ 23-6-1 to 23-6-9. Available online: https://library.municode.com/mi/detroit/codes/code_of_ ordinances?nodeId=PTIVDECO_CH23HURI (accessed on 20 June 2020). 
6. National Fair Housing Alliance. Making Every Neighborhood A Place of Opportunity: 2018 Fair Housing Trends Report. 2018. Available online: https://nationalfairhousing.org/wp-content/uploads/2018/04/NFHA2018-Fair-Housing-Trends-Report.pdf (accessed on 20 June 2020).

7. National Fair Housing Alliance. 2019 Fair Housing Trends Report. 2019. Available online: https://nationalfairhousing. org/2019-fair-housing-trends-report/ (accessed on 20 June 2020).

8. Rohe, W.M.; Zandt, S.V.; McCarthy, G. Home Ownership and Access to Opportunity. Hous. Stud. 2002, 17, 51-61. [CrossRef]

9. Abravanel, M.D. Do We Know More Now? Trends in Public Knowledge, Support and Use of Fair Housing Law. 2006. Available online: https://www.huduser.gov/portal//Publications/pdf/FairHousingSurveyReport.pdf (accessed on 20 November 2020).

10. Abravanel, M.; Cunningham, M.K. How Much Do We Know? Public Awareness of the Nation's Fair Housing Laws. Available online: https://www.huduser.gov/Publications/pdf/hmwk.pdf (accessed on 30 November 2020).

11. Galster, G. Urban Gentrification: Evaluating Alternative Indicators. Soc. Ind. Res. 1986, 18, 321-337. [CrossRef]

12. Ross, S.L.; Turner, M.A. Housing Discrimination in Metropolitan America: Explaining Changes between 1989 and 2000. Soc. Probl. 2005, 52, 152-180. [CrossRef]

13. Yinger, J. Housing discrimination is still worth worrying about. Hous. Policy Debate 1998, 9, 893-927. [CrossRef]

14. Dymski, G.A. The theory of bank redlining and discrimination: An exploration. Rev. Black Politi-Econ 1995, 23, 37-74. [CrossRef]

15. Turner, M.A. Mortgage Lending Discrimination: A Review of Existing Evidence. Urban Institute. 1999. Available online: http://webarchive.urban.org/publications/309090.html (accessed on 14 June 2020).

16. Yinger, J. Measuring racial discrimination with fair housing audits: Caught in the act. Am. Econ. Rev. 1986, 76, 881-893.

17. Galster, G. The ecology of racial discrimination in housing: An exploratory model. Urban Aff. Q. 1987, $23,84-107$. [CrossRef]

18. Aigner, D.J.; Cain, G.G. Statistical Theories of Discrimination in Labor Markets. Ind. Labor Relat. Rev. 1977, 30, 175-187. [CrossRef]

19. Phelps, E.S. The Statistical Theory of Racism and Sexism. Am. Econ. Rev. 1972, 62, 659-661.

20. Flage, A. Ethnic and gender discrimination in the rental housing market: Evidence from a meta-analysis of correspondence tests, 2006-2017. J. Hous. Econ. 2018, 41, 251-273. [CrossRef]

21. Galster, G.; Constantine, P. Discrimination Against Female-Headed Households in Rental Housing: Theory and Exploratory Evidence. Rev. Soc. Econ. 1991, 49, 76-100. [CrossRef]

22. Rice, L.; Swesnik, D. Discriminatory Effects of Credit Scoring on Communities of Color. Suffolk U. L. Rev. 2013, 46, 935 .

23. Williams, L. African American Homeownership and the Dream Deferred: A Disparate Impact Argument against the Use of Credit Scores in Homeownership Insurance Underwriting. Conn. Ins. L.J. 2008, 15, 295.

24. Bell, J.; Lee, M. Why Place \& Race Matter (Full Report). 2011. Available online: http://www.policylink.org/ find-resources/library/why-place-and-race-matter (accessed on 15 May 2020).

25. Turner, M.A.; Santos, R.; Levy, D.K.; Wissoker, D.A. Housing Discrimination against Racial and Ethnic Minorities 2012: Full Report. Urban Institute. 2016. Available online: https://www.urban.org/research/publication/housingdiscrimination-against-racial-and-ethnic-minorities-2012-full-report (accessed on 20 May 2020).

26. Myers, C.K. Discrimination and neighborhood effects: Understanding racial differentials in US housing prices. J. Urban Econ. 2004, 56, 279-302. [CrossRef]

27. Denton, N.A. Segregation and Discrimination in Housing. In A Right to Housing: Foundation for a New Social Agenda; Bratt, R.G., Bratt, M.E., Hartman, C.W., Eds.; Temple University Press: Philadelphia, PA, USA, 2006; pp. 61-79.

28. Roscigno, V.J.; Karafin, D.L.; Tester, G. The complexities and processes of racial housing discrimination. Soc. Prob. 2009, 56, 49-69. [CrossRef]

29. Rugh, J.S.; Massey, D.S. Racial Segregation and the American Foreclosure Crisis. Am. Sociol. Rev. 2010, 75, 629-651. [CrossRef]

30. Kearney, M.S.; Levine, P.B. Income Inequality, Social Mobility, and the Decision to Drop Out of High School (Brookings Paper on Economic Activity). 2016. Available online: https:/www.brookings.edu/wp-content/ uploads/2016/03/kearneytextspring16bpea.pdf (accessed on 13 December 2020). 
31. Reardon, S.F.; Owens, A. 60 Years After Brown: Trends and Consequences of School Segregation. Annu. Rev. Soc. 2014, 40, 199-218. [CrossRef]

32. Acevedo-Garcia, D.; Noelke, C.; McArdle, N.; Sofer, N.; Hardy, E.F.; Weiner, M.; Baek, M.; Huntington, N.; Huber, R.; Reece, J. Racial And Ethnic Inequities In Children's Neighborhoods: Evidence From The New Child Opportunity Index 2.0. Health Aff. 2020, 39, 1693-1701. [CrossRef]

33. Debbink, M.P.; Bader, M.D.M. Racial residential segregation and low birth weight in Michigan's Metropolitan Areas. Am. J. Public Health 2011, 101, 1714-1720. [CrossRef] [PubMed]

34. Morello-Frosch, R.; Jesdale, B.M. Separate and unequal: Residential segregation and estimated cancer risks associated with ambient air toxics in U.S. Metropolitan Areas. Environ. Health Perspect 2006, 114, 386-393. [CrossRef] [PubMed]

35. Hart, K.D.; Kunitz, S.J.; Sell, R.R.; Mukamel, D.B. Metropolitan governance, residential segregation, and mortality among African Americans. Am. J. Public Health 1998, 88, 434-438. [CrossRef] [PubMed]

36. U.S. Census Bureau American Community Survey (5-Year Estimates). 2018. Available online: https://www. census.gov/acs/www/data/data-tables-and-tools/data-profiles/2018/ (accessed on 15 November 2020).

37. Farley, R.; Danziger, S.; Holzer, H.J. Detroit Divided; Russell Sage Foundation: New York, NY, USA, 2002.

38. Sugrue, T.J. The Origins of the Urban Crisis: Race and Inequality in Postwar Detroit; Princeton University Press: Princeton, NJ, USA, 2014.

39. Gotham, K.F. Racialization and the State: The Housing Act of 1934 and the Creation of the Federal Housing Administration. Sociol. Perspect. 2000, 43, 291-317. [CrossRef]

40. Darden, J.T.; Hill, R.C.; Thomas, J.; Thomas, R. Detroit: Race and Uneven Development; Temple University Press: Philadelphia, PA, USA, 1987.

41. Phinney, S. Detroit's Municipal Bankruptcy: Racialised geographies of austerity. New Political Economy 2018, 23, 609-626. [CrossRef]

42. Eisenberg, A.; Mehdipanah, R.; Dewar, M. 'It's like they make it difficult for you on purpose': Barriers to property tax relief and foreclosure prevention in Detroit, Michigan. Housing Studies 2020, 35, 1415-1441. [CrossRef]

43. Joint Center for Housing Studies of Harvard University A New Decade of Growth for Remodeling: Improving America's Housing. 2011. Available online: https://www.jchs.harvard.edu/sites/default/files/ 2011_remodeling_color.pdf (accessed on 25 June 2020).

44. Dewar, M.; Seymour, E.; Druță, O. Disinvesting in the city: The role of tax foreclosure in Detroit. Urban Aff. Rev. 2015, 51, 587-615. [CrossRef]

45. U.S. Census Bureau. Census 2000. 2000. Available online: https://www.census.gov/main/www/cen2000.html (accessed on 20 July 2020).

46. Fair Housing Detroit (n.d.). Available online: http://www.fairhousingdetroit.org/ (accessed on 14 January 2017).

47. Schulz, A.J.; Zenk, S.; Kannan, S.; Israel, B.A.; Stokes, C. Community-based participatory approach to survey. In Methods for Community-Based Participatory Research for Health; Jossey-Bass: San Francisco, CA, USA, 2013; pp. 197-223.

48. Healthy Environment Partnership (n.d.) Community Based Participatory Research (CBPR). Available online: http://www.hepdetroit.org/en/hep-overview/cbpr (accessed on 14 January 2017).

49. Mehdipanah, R.; Schulz, A.J.; Israel, B.A.; Gamboa, C.; Rowe, Z.; Khan, M.; Allen, A. Urban HEART Detroit: A tool to better understand and address health equity gaps in the city. J. Urban Health 2017, 1-10. [CrossRef]

50. Schulz, A.J.; Zenk, S.; Odoms-Young, A.; Hollis-Neely, T.; Nwankwo, R.; Lockett, M.; Ridella, W.; Kannan, S. Healthy Eating and Exercising to Reduce Diabetes: Exploring the Potential of Social Determinants of Health Frameworks Within the Context of Community-Based Participatory Diabetes Prevention. Am. J. Public Health 2005, 95, 645-651. [CrossRef]

51. Aranda, C. Fighting Housing Discrimination in 2019. 2019. Available online: https://www.urban.org/urbanwire/fighting-housing-discrimination-2019 (accessed on 18 November 2020).

52. Bentley, R.; Baker, E.; Mason, K.; Subramanian, S.V.; Kavanagh, A.M. Association between housing affordability and mental health: A longitudinal analysis of a nationally representative household survey in Australia. Am. J. Epidemiol. 2011, 174, 753-760. [CrossRef]

53. Macintyre, S.; Ellaway, A.; Der, G.; Ford, G.; Hunt, K. Do housing tenure and car access predict health because they are simply markers of income or self esteem? A Scottish study. J. Epidemiol. Community Health 1998, 52, 657-664. [CrossRef] [PubMed] 
54. Ortiz, S.E.; Zimmerman, F.J. Race/ethnicity and the relationship between homeownership and health. Am. J. Public Health 2013, 103, e122-e129. [CrossRef] [PubMed]

55. Lindblad, M.R.; Manturuk, K.R.; Quercia, R.G. Sense of Community and Informal Social Control Among Lower Income Households: The Role of Homeownership and Collective Efficacy in Reducing Subjective Neighborhood Crime and Disorder. Am. J. Community Psychol. 2013, 51, 123-139. [CrossRef] [PubMed]

56. Haurin, D.R.; Dietz, R.D.; Weinberg, B.A. The Impact of Neighborhood Homeownership Rates: A Review of the Theoretical and Empirical Literature (SSRN Scholarly Paper ID 303398). Social Science Research Network. 2002. Available online: https://papers.ssrn.com/abstract=303398 (accessed on 2 April 2020).

57. Ross, A.; Talmage, C.A.; Searle, M. Toward a Flourishing Neighborhood: The Association of Happiness and Sense of Community. Appl. Res. Qual. Life 2019, 14, 1333-1352. [CrossRef]

58. U.S. Department of Housing and Urban Development (HUD) Housing Discrimination Under the Fair Housing Act. 2004. Available online: https://www.hud.gov/program_offices/fair_housing_equal_opp/fair_ housing_act_overview (accessed on 6 February 2020).

59. Akers, J.; Seymour, E. Instrumental exploitation: Predatory property relations at city's end. Geoforum 2018, 91, 127-140. [CrossRef]

60. Mehdipanah, R. Housing as a Determinant of COVID-19 Inequities. Am. J. Public Health 2020, 110, 1369-1370. [CrossRef]

61. Benfer, E.; Robinson, D.B.; Butler, S.; Edmonds, L.; Gilman, S.; McKay, K.L.; Neumann, Z.; Owens, L.; Steinkamp, N.; Yentel, D. The COVID-19 Eviction Crisis: An Estimated 30-40 Million People in America Are at Risk. Available online: https://www.aspeninstitute.org/blog-posts/the-covid-19-eviction-crisis-anestimated-30-40-million-people-in-america-are-at-risk/ (accessed on 18 November 2020).

62. Greiner, D.J.; Pattanayak, C.W.; Hennessy, J. The Limits of Unbundled Legal Assistance: A Randomized Study in a Massachusetts District Court and Prospects for the Future. Harv. L. Rev. 2012, 126, 901. [CrossRef]

63. Porton, A.; Gromis, A.; Desmond, M. Inaccuracies in Eviction Records: Implications for Renters and Researchers. Hous. Policy Debate 2020, 1-18. [CrossRef]

64. Desmond, M.; Kimbro, R.T. Eviction's fallout: Housing, hardship and health. Soc. Forces 2015, 1-30. [CrossRef]

65. Rojas, Y.; Stenberg, S.-Å. Evictions and suicide: A follow-up study of almost 22,000 Swedish households in the wake of the global financial crisis. J. Epidemiol. Community Health 2016, 70, 409-413. [CrossRef]

66. Van Laere, I.; De Wit, M.; Klazinga, N. Preventing evictions as a potential public health intervention: Characteristics and social medical risk factors of households at risk in Amsterdam. Scand. J. Public Health 2009, 37, 697-705. [CrossRef] [PubMed]

67. Buchanan v. Warley, 245 U.S. 60 (1917). Available online: https://supreme.justia.com/cases/federal/us/245/60/ (accessed on 30 November 2020).

68. Fischel, W.A. An Economic History of Zoning and a Cure for its Exclusionary Effects. Urban Stud. 2004, 41,317-340. [CrossRef]

69. Silver, C. The racial origins of zoning in American cities. In Urban Planning and the African American Community: In the Shadows; Manning Thomas, J., Ritzdorf, M., Eds.; Sage Publications: Thousand Oaks, CA, USA, 1997; pp. 23-42.

70. Freund, D.M.P. Colored Property: State Policy and White Racial Politics in Suburban America; Illustrated edition; University of Chicago Press: Chicago, IL, USA, 2010.

71. Rothwell, J.; Massey, D.S. The Effect of Density Zoning on Racial Segregation in U.S. Urban Areas. Urban Aff. Rev. 2009. [CrossRef]

72. Cassidy, J. Detroit: The Evolution of a Housing Crisis. 2019. Available online: https://mlpp.org/detroit-theevolution-of-a-housing-crisis/ (accessed on 6 June 2020).

73. Carr, J.H. The Complexity of Segregation: Why it Continues 30 Years After the Enactment of the Fair Housing Act. Cityscape 1999, 4, 139-146.

74. Rothstein, R. The Color of Law; Liveright Publishing Corporation: New York, NY, USA, 2017.

75. National Fair Housing Alliance. Unequal Opportunity-Perpetuating housing segregation in America (p. 30). National Fair Housing Alliance. 2006. Available online: https://nationalfairhousing.org/wp-content/ uploads/2017/04/trends2006.pdf (accessed on 8 August 2020).

76. U.S. Department of Housing and Urban Development (HUD). HUD Charges Facebook with Housing Discrimination over Company's Targeted Advertising Practices. Available online: https:/www.hud.gov/ press/press_releases_media_advisories/HUD_No_19_035 (accessed on 13 December 2020). 
77. Booker, B. Housing Department Slaps Facebook With Discrimination Charge. National Public Radio (NPR). 2019. Available online: https://www.npr.org/2019/03/28/707614254/hud-slaps-facebook-with-housingdiscrimination-charge (accessed on 11 November 2020).

78. Khatry, S. Facebook and Pandora's box: How using Big Data and Artificial Intelligence in advertising resulted in housing discrimination. Appl. Mark. Anal. 2020, 6, 37-45.

79. National Fair Housing Alliance. 2017 Fair Housing Trends Report. 2017. Available online: http://nationalfairhousing. org/2017-fair-housing-trends-report/ (accessed on 6 June 2020).

80. Beard, J.R.; Blaney, S.; Cerda, M.; Frye, V.; Lovasi, G.S.; Ompad, D.; Rundle, A.; Vlahov, D. Neighborhood characteristics and disability in older adults. J. Gerontol. Ser. B 2009, 64, 252-257. [CrossRef] [PubMed]

81. Schmitz, N.; Nitka, D.; Gariepy, G.; Malla, A.; Wang, J.; Boyer, R.; Messier, L.; Strychar, I.; Lesage, A. Association between neighborhood-level deprivation and disability in a community sample of people with diabetes. Diabetes Care 2009, 32, 1998-2004. [CrossRef] [PubMed]

82. U.S. Department of Housing and Urban Development (HUD); U.S. Department of Justice. Joint Statement of the Department of Housing and Urban Development and the Department of Justice Reasonable Accommodations under the Fair Housing Act. 2004. Available online: https:/www.justice.gov/sites/ default/files/crt/legacy/2010/12/14/joint_statement_ra.pdf (accessed on 11 November 2020).

Publisher's Note: MDPI stays neutral with regard to jurisdictional claims in published maps and institutional affiliations.

(C) 2020 by the authors. Licensee MDPI, Basel, Switzerland. This article is an open access article distributed under the terms and conditions of the Creative Commons Attribution (CC BY) license (http://creativecommons.org/licenses/by/4.0/). 